\title{
Left Main Coronary Artery Stenosis
}

National Cancer Institute

\section{Source}

National Cancer Institute. Left Main Coronary Artery Stenosis. NCI Thesaurus. Code C80428.

Percent luminal narrowing of the left main coronary artery, at the point of maximal stenosis of the left main coronary artery. 